\title{
Urdimento
}

Revista de Estudos em Artes Cênicas

E-ISSN: 2358.6958

\section{O Teatro entre as grades do patriarcado: privação de liberdade e de experiências em uma prática no regime socioeducativo}

Laís Jacques Marques, Vicente Concilio, Túlio Fernandes Silveira, Flávia Machado

\section{Para citar este artigo:}

MARQUES, Laís Jacques; CONCILIO, Vicente; SILVEIRA, Túlio Fernandes; MACHADO, Flávia. O Teatro entre as grades do patriarcado: privação de liberdade e de experiências em uma prática no regime socioeducativo. Urdimento, Florianópolis, v. 3, n. 39, nov./dez. 2020.

DOI: http:/dx.doi.org/10.5965/14145731033920200119

Este artigo passou pelo Plagiarism Detection Software | iThenticate 


\title{
O Teatro entre as grades do patriarcado: privação de liberdade e de experiências em uma prática no regime socioeducativo'
}

\author{
Laís Jacques Marques², Vicente Concilio ${ }^{3}$, \\ Túlio Fernandes Silveira ${ }^{4}$, Flávia Machado ${ }^{5}$
}

\begin{abstract}
Resumo
O presente artigo visa relatar práticas de pesquisadoras de Teatro com jovens em cumprimento de medidas socioeducativas e em privação de liberdade. O mesmo investigará a pedagogia do teatro junto aos jovens nos setores feminino e masculino de uma instituição socioeducativa catarinense, com a perspectiva do entorno do processo: as relações de poder estipuladas e visíveis não só entre internas(os) e funcionárias(os) do centro, como também os motivos que implicaram e interferiram na prática teatral. As opções da ação artístico-pedagógica das oficinas serão exemplificadas a fim de expor o percurso trilhado na prática pedagógica e teatral.
\end{abstract}

Palavras-chave: Pedagogia do Teatro. Socioeducação. Teatro e juventude.

\footnotetext{
${ }^{1}$ Revisora português: Jucilene Orlandi, professora de Língua Portuguesa aposentada da rede pública estadual de Santa Catarina.

${ }^{2}$ Mestranda do Programa de Pós-Graduação em Teatro da Universidade do Estado de Santa Catarina (UDESC); Graduanda em Licenciatura em Teatro pela Universidade Federal de Santa Maria (UFSM); Bacharela em Artes Cênicas - Interpretação Teatral pela Universidade Federal de Santa Maria (UFSM) - 2017. laisjacquesm@gmail.com

3 Professor Doutor do Departamento de Artes Cênicas da Universidade do Estado de Santa Catarina (UDESC), e do Programa de Pós-graduação em Teatro e o Mestrado Profissional em Artes - ProfArtes da mesma universidade. viconcilio@gmail.com

${ }^{4}$ Graduando de Licenciatura em Teatro pela Universidade do Estado de Santa Catarina (UDESC). Professor de teatro em formação, pesquisador e ator. Bolsista do programa de pesquisa "Teatro e prisão: práticas de infiltração das artes cênicas em espaços de vigilância”. tulio.fs@hotmail.com

${ }^{5}$ Graduanda de Licenciatura em Teatro pela Universidade do Estado de Santa Catarina (UDESC). Professora de teatro em formação e pesquisadora. Bolsista do programa de pesquisa "Teatro e prisão: práticas de infiltração das artes cênicas em espaços de vigilância". flavia11machado@gmail.com
} 


\title{
Theater between the patriarchy bars: deprivation of freedom and experiences in a practice in the socio-educational regime
}

\begin{abstract}
This article describes the practices of theater researchers offering programming, that meets recognized educational standards, for youth in carceral settings. The article investigates the pedagogy of theater with young people in the female and male sides of a youth facility in Santa Catarina and examines the conditions that surround the process pf theatre making in such a setting. The power dynamics between residents and employees of the facility imbued the work and interfered in the theatrical practice. The article lays out what options for artistic and pedagogical action existed in the workshop and ultimately explains pedagogical and theatrical practice that resulted.
\end{abstract}

Keywords: Theater Pedagogy. Socio-education. Theater and youth.

Teatro entre rejas del patriarcado: privación de libertad y vivencias en una práctica en el régimen socioeducativo

\section{Resumen}

Este artículo tiene como objetivo reportar a las prácticas de los investigadores teatrales con jóvenes en cumplimiento de medidas socioeducativas y en privación de libertad. El mismo cuestionará el aporte de la pedagogía del teatro con jóvenes de los sectores femenino y masculino de una institución socioeducativa en Santa Catarina con miradas hacia al entorno del proceso: las relaciones de poder establecidas y visibles, no solo entre los internos y empleados del centro, sino también las razones que cruzan e interfieren en la práctica teatral. Se ejemplificarán las propuestas de acción artística y pedagógica en los talleres con el fin de exponer el camino recorrido en la práctica pedagógica y teatral.

Palabras clave: Pedagogía teatral. Socio educación. Teatro y juventud. 
O presente artigo apresenta relatos de docentes de Teatro com jovens em privação de liberdade. Nosso objetivo para além das discussões pedagógicas e teatrais que tangenciam a prática com o recorte sobre ambientes de vigilância, abordará como os padrões heteronormativos se configuram - e interferem nas práticas artísticas - em ambientes socioeducativos. Durante o artigo, traremos relatos sobre as aulas de Teatro ministradas nas alas femininas (CIF) ${ }^{6}$ e masculinas $(\mathrm{CASE})^{7}$ de uma unidade do Departamento de Administração Socioeducativo $(D E A S E)^{8}$ no estado de Santa Catarina. Ressaltamos que o planejamento inicial das aulas foi o mesmo para ambos os grupos, entretanto, em se tratando de aulas de Arte - que respeitam as individualidades de todos os sujeitos - o desenvolvimento do trabalho se deu de forma distinta. Aqui, nos interessa guiar a escrita a partir de nossas experiências iniciais no regime socioeducativo.

Elaborar o relato a partir de nossas vivências, nos fez questionar o quanto e o que pode o Teatro em ambientes de privação de liberdade. Qual é o papel do Teatro em locais como o sistema socioeducativo? Como tornar o Teatro necessário em ambientes de privação de liberdade? E quais os motivos que fazem com que o Teatro, por vezes, seja impedido de permanecer nesses espaços? Essas questões não visam serem respondidas no escrito, mas ecoam no nosso desenvolvimento enquanto condutoras de práticas teatrais em espaços de vigilância.

Pretendemos materializar em texto as inquietações e frustrações causadas por conflitos experienciados no regime socioeducativo. Aqui, trataremos dos embates vivenciados na ala masculina da instituição, onde fomos, de forma abrupta, levadas a interromper as atividades em decorrência de indícios de

\footnotetext{
${ }^{6}$ Centro de Internação Feminina (CIF).
}

${ }^{7}$ Centro de Acolhimento Socioeducativo (CASE).

${ }^{8}$ O Departamento de Administração Socioeducativa (DEASE) é um órgão subordinado à Secretaria de Estado da Administração Prisional e Socioeducativa (SAP), e abriga jovens em conflito com a lei, que possuem entre 16 até 21 anos. Separados entre ala feminina (Centro de Internação Feminina - CIF) e masculina (Centro de Atendimento Socioeducativo - CASE), conta com aproximadamente 35 jovens. O projeto, vinculado ao grupo que pesquisa Teatro e Prisão da Universidade do Estado de Santa Catarina (UDESC), previu aulas de Teatro em ambas as alas, porém as mesmas se efetivaram somente no CIF, até fevereiro de 2020. Os motivos da saída da ala masculina serão relatados ao longo do texto. Com as medidas de isolamento social ocasionadas pelo Covid-19, as aulas na unidade foram suspensas. 
comportamentos preconceituosos por parte de membros da instituição para com o fazer teatral e para com a orientação sexual das professoras. Conflitos esses que serão debatidos ao longo do texto, e que compreendemos como naturalizados

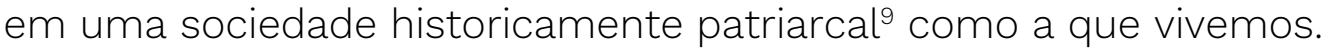

A filósofa estadunidense Angela Davis (2019) aborda o assunto no contexto prisional, mas relacionamos ao regime socioeducativo por compreendermos que o sistema de internação juvenil é um embrião do sistema prisional adulto ${ }^{10}$. Segundo ela, quanto ao que diferencia a internação de mulheres e de homens que cometem atos infracionais: "ao passo que os criminosos do sexo masculino eram considerados indivíduos que tinham simplesmente violado o contrato social, as criminosas eram vistas como mulheres que tinham transgredido princípios morais fundamentais da condição feminina" (Davis, 2019, p.75-76). Uma afirmação como essa evidencia o cerne da problemática que acompanhamos em micro escala e que reflete a naturalização do machismo estrutural em sociedades patriarcais. 0 que enxergamos e que utilizaremos como recorte - nossa experiência - é somente o ponto de partida das inquietações que se infiltram por detrás das grades.

Apontaremos nossas questões a partir da obra de pesquisadoras(es) que abordam a relação entre as instituições punitivas e pessoas em privação de liberdade. Tais como a filósofa estadunidense Angela Davis (2018, 2019) que manifesta a necessidade de repensar o sistema punitivista; o teatrólogo brasileiro Augusto Boal $(1977,2003)$ que relata suas experiências com Teatro em prisões; e a historiadora brasileira Juliana Borges (2019) que problematiza questões como o encarceramento em massa e o exponencial crescimento da população carcerária feminina no Brasil. Além desses, o sociólogo brasileiro Fábio Mallart (2014) que aborda a relevância do debate acerca das medidas disciplinares com o olhar

\footnotetext{
${ }^{9}$ Compreendemos o conceito de patriarcado a partir da socióloga brasileira Heleieth Saffioti (1934 - 2010) na obra Gênero, Patriarcado, Violência (2004), que apresenta os reflexos do machismo em casos de estupro e de relações incestuosas - não necessariamente relacionados ao contexto prisional, mas sim com o recorte das classes sociais no Brasil.

10 Segundo as pesquisadoras da área da psicologia, Luisa Bertrami D'Angelo e Jimena de Garay Hernandes (2017) em Sexualidade, um direito (secundário)? Atravessamentos entre sexualidade, socioeducação e punição, a diferença principal do regime socioeducativo aos olhos das administrações destes centros, são os direitos (questionáveis) à visita íntima. Retomaremos o assunto adiante.
} 
centralizado para a juventude privada de liberdade no Brasil.

\section{Cenário: a chegada na instituição}

A rotina institucional, marcada pela repetição e pela rigidez disciplinar que se traduz no controle incessante, por parte dos agentes institucionais do tempo e dos movimentos corporais dos internos produz a sensação de que as horas não passam, dando a impressão de que todos os dias são iguais, o amanhã sendo apenas a antecipação do hoje (Mallart, 2014, p. 52).

O sociólogo brasileiro Fábio Mallart"11, a partir de oficinas de fotografia ${ }^{12}$ realizadas na fundação socioeducativa CASA $^{13}$, revela a importância de ações culturais e artísticas com jovens em privação de liberdade. Aqui, julgamos relevante abordar nossas ações enquanto integrantes do projeto de pesquisa Teatro e Prisão - práticas de infiltração das artes cênicas em espaços de vigilância ${ }^{14}$ da Universidade do Estado de Santa Catarina (UDESC). O grupo de pesquisa promove ações teatrais com pessoas em privação de liberdade. A iniciativa tem como objetivo efetivar estudos teóricos do Teatro nesses locais, além de dialogar sobre práticas em presídios e instituições socioeducativas.

A atuação do grupo de pesquisa começou em agosto de 2017, com aulas de Teatro ministradas no Presídio Feminino de Florianópolis - SC e culminou na realização do espetáculo teatral Estendemos nossas memórias ao sol ${ }^{5}$ apresentado na capital do estado. A partir da iniciativa, foi possível atuar também

${ }^{11}$ Em Cadeias Dominadas: A Fundação CASA, suas dinâmicas e as trajetórias de jovens internos (2014), Mallart relata o desenvolvimento histórico de instituições socioeducativas em São Paulo - SP.

12 Ibidem, 2014.

${ }^{13}$ Centro de Acolhimento Socioeducativo de São Paulo capital.

${ }^{14} \mathrm{Na}$ ocasião, o grupo de pesquisa era formado por sete integrantes, entre bolsistas de pesquisa e extensão da graduação e do mestrado, coordenado pelo Professor Doutor Vicente Concilio. Hoje, está vinculado ao grupo Pedagogia das Artes Cênicas da UDESC e compõe a rede de pesquisa e atuação do Observatório de práticas artísticas no cárcere e em espaços de privação de liberdade, da Universidade Federal do Estado do Rio de Janeiro (UNIRIO) e a University of Michigan, voltada para o Teatro com pessoas em privação de liberdade.

15 Estendemos nossas memórias ao sol é uma peça de teatro protagonizada por mulheres em privação de liberdade, que teve sua estreia em outubro de 2019, e é resultado das práticas teatrais do grupo de pesquisa iniciadas em fevereiro do mesmo ano no presídio feminino de Florianópolis - SC. 
no regime socioeducativo - a convite do corpo diretivo da instituição que entrou em contato com o coordenador do grupo e solicitou ações teatrais que contemplassem jovens em privação de liberdade. Nossa participação na instituição que abriga jovens em conflito com a lei ampliou a rede que estava sendo tecida. Eis, então, nosso campo de análise e de investigações para essa escrita.

Sobre o grupo de atuação no sistema socioeducativo, nos dividimos entre uma graduanda por ala (um graduando na ala masculina e uma graduanda na ala feminina) com a participação da mestranda em ambas, sob a supervisão do coordenador do grupo e da profissional do setor pedagógico da instituição.

Do cenário local Socioeducativo: o estado de Santa Catarina possui o segundo maior número de unidades de internação do Brasil ${ }^{16}$. Sobre o regime socioeducativo catarinense, segundo informações disponibilizadas no endereço eletrônico do DEASE, sabemos que:

[...] foi instituído como normativa pelo CONANDA/SDH na forma estabelecida pelo Estatuto da Criança e do Adolescente (ECA), para atender adolescentes de ambos os sexos aos quais se atribua autoria de ato infracional.[...] O comprometimento e humanização devem perpassar imprescindivelmente pela valorização da pessoa, respeitando e reconhecendo a adolescência como etapa única do desenvolvimento humano. O período de três anos da adolescência, prazo máximo da aplicação da medida socioeducativa de internação, traduz-se em metade deste momento tão singular da vida, por isso, especial e merecedor de cuidados. Integra a lógica da socioeducação, os princípios da incolumidade, integridade física e segurança, na perspectiva do Estado assumir as funções de: cuidar, zelar e participar do processo de construção de seus cidadãos. ${ }^{17}$

No início das atividades criamos inevitáveis expectativas, sendo uma delas a de que o local condizesse com os objetivos e missões predeterminados pela instituição: que fosse acolhedor (como sugere a sigla) e que houvesse preocupação

\footnotetext{
${ }^{16}$ Santa Catarina possui 28 unidades socioeducativas, segundo o Conselho Nacional do Ministério Público em Panorama da execução dos programas socioeducativos de internação e semiliberdade nos estados brasileiros. Brasília, 2019.
}

17 Santa Catarina. Departamento de Administração Socioeducativo. Disponível em: http://www.dease.sc.gov.br/institucional/historico-e-missao. Acesso em: 15 de jun. de 2020. 
com "a formação de adolescentes autônomos, cidadãos solidários e profissionais competentes, possibilitando a construção de projetos de vida, além da convivência familiar e comunitária plena"18. Assim partimos, reflexivas quanto ao desafio de como infiltrar o Teatro na rotina das e dos jovens internas(os). Inspiradas pelo que discute o teatrólogo alemão Florian Vassen, em artigo traduzido pela teatróloga brasileira Ingrid Koudela, concordamos que:

O teatro como arte de sociabilidade parece ser mais forte do que desenhar ou pintar, escrever ou ler e até cantar ou mesmo aprender um instrumento - uma forma de arte social e multidimensional. O teatro oferece como espaço a base para a reunião, o encontro, e assim possibilita a criatividade coletiva; ou seja, é socializante e, portanto, enfaticamente social. Nisso exerce um papel importante, pelo fato de a práxis teatral construir-se como um evento comunitário, por intermédio do qual se desenvolve uma forma de arte cooperativa que se baseia em uma inteligência coletiva [...] (Vassen, 2014, p.13-14, grifo do autor).

Assim como Vassen (2014), entendemos o Teatro como aliado na busca por autonomia. Entretanto, sem negar seus feitos, os estereótipos que associam o Teatro a uma visão de feminilidade tornou-se um problema na ala masculina. No processo de reconhecimento do local e do corpo institucional, percebemos que enfrentaríamos questões problemáticas no que tange o preconceito acerca de práticas artísticas e que se acentuam em contextos de privação de liberdade em centros de acolhimentos masculinos.

\section{Dos nossos objetivos à realidade: conversas de coxia}

Corrigir as pessoas sempre foi um objetivo ligado ao uso que se quer fazer delas (Rocha, 1996, p.170).

Em concordância à reflexão do brasileiro e psicólogo social Dr. Luiz Carlos da Rocha $^{19}$, acreditamos que o projeto de vida das pessoas que cometem atos

\footnotetext{
18 Ibidem.

${ }^{19}$ Rocha, 1994.
} 
infracionais, aos olhos das instituições punitivas, subentendem intuitos ligados ao o quê delas pode interessar às instituições.

Como parte do processo de formação docente, preparamos as aulas de acordo com o que nos foi apresentado durante a graduação e conforme as regras definidas pela instituição. Ressaltamos que a elaboração do projeto (os planos de aula e as metodologias que adotaríamos para efetivar a pesquisa) se deu como parte do processo em conjunto às visitas à instituição, as aulas que ministramos, e às reuniões com o grupo de pesquisa, evidenciando o aspecto da investigação pedagógica na prática.

Ressaltamos que nosso olhar estava atento não apenas à perspectiva da metodologia de trabalho - visto que nos adaptávamos conforme as exigências do local e das experiências relacionais com as(os) jovens -, mas também com o que acontecia ao nosso redor, tanto na relação das(os) jovens com a equipe de segurança e administrativa do local, quanto com o que reverberava em nossas aulas. Reverberações essas que abordaremos ao longo do texto.

As inúmeras orientações que recebemos de integrantes da administração serviram como uma espécie de condicionantes no trato com as(os) jovens. Entre permissões e proibições, foi sugerido evitar a criação de vínculos afetivos com as(os) internas(os), a fim de impedir possíveis solicitações e requerimentos de favores extramuros. Na nossa primeira reunião, percebemos que a perspectiva para o trabalho não passaria pelo campo da prática teatral processual, de cunho pedagógico, como imaginávamos. Presumimos que a visão de trabalhos artísticos, por parte da administração do local, enfatizava resultados e não processos como era de nosso interesse.

O que interessava à instituição era principalmente a capacitação das(os) jovens e não a experiência libertadora e emancipatória que o Teatro é capaz de proporcionar. Talvez isso explique o motivo pelos quais tantas oficinas disponibilizadas no CASE não foram concluídas (como nos informou a direção), já que o intuito de conscientização social e artística era diminuído perante os objetivos mercadológicos das ações. As únicas oficinas permanentes eram de 
fabricação de bolsas a partir de materiais recicláveis, as quais as(os) jovens produziam e vendiam, com a mediação do DEASE. Ou seja, a Arte era vista somente com um viés de rentabilidade. Eis o início das nossas frustrações.

Ao fim da primeira reunião, ouvimos de integrantes da coordenação da instituição algo que ressoou não somente em nosso trabalho, mas na imagem que até então construíamos de pessoas que têm como realidade a privação de liberdade desde a juventude. Para a equipe administrativa, as(os) jovens possuem dois caminhos ao saírem da instituição socioeducativa: a prisão ou a morte. 0 fatalismo com que visualizam o futuro das pessoas internas nos direcionou ao que coloca Davis (2018) que, em A liberdade é uma luta constante, nos diz que os esforços punitivistas são simplistas e não corroboram para uma sociedade livre de violência:

Basta mandar essas pessoas para a prisão. Basta continuar a mandá-las para a prisão. E então, óbvio, na prisão elas se veem dentro de uma instituição violenta e que reproduz violência. De muitas maneiras, podese dizer que a instituição se alimenta dessa violência e a reproduz, de modo que, quando a pessoa é libertada, provavelmente se tornou pior. (Davis, 2018, p.36).

A opressão relatada pela autora não foi explicitamente observada na unidade socioeducativa, porém a obstaculização ao acesso às práticas teatrais configura uma outra forma de violência contra o direito pré-estabelecido de jovens à cultura. Conforme apontado pelo Estatuto da Criança e do Adolescente (ECA), lemos que: "No processo educacional respeitar-se-ão os valores culturais, artísticos e históricos próprios do contexto social da criança e do adolescente, garantindo-se a estes a liberdade da criação e o acesso às fontes de cultura." (ECA, 1990, Art.58).

Argumentamos sobre a relevância da prática teatral, pois conceitualmente nosso trabalho não resultaria em um bem concreto, material, rentável, portanto segundo os objetivos do sistema, a prática, dificilmente, seria bem aceita pelas(os) jovens. Nossa estratégia para reverter o possível desinteresse foi elaborar certificados com a carga horária da oficina, no intuito de profissionalizá-las(os). Entretanto, o que nos interessava era tornar a aula de teatro um espaço democrático, que motivasse-as(os) a desenvolver visão de processos artísticos 
sem o intuito de resultados finais de apresentações de arte. Nos interessava que compreendessem a dimensão do fazer artístico pedagógico pela relevância do processo, e que levassem consigo os aprendizados de coletividade e de interrelação para além dos muros - saberes que, ao nosso ver, o Teatro estimula.

Notamos que nossos recursos seriam limitados, já que os assuntos tratados deveriam ser restritos. Tínhamos que evitar abordar temas polêmicos como por exemplo, a realidade das vidas daquelas(es) jovens para além dos muros (da violência, da criminalidade, do uso de drogas, do sexo, etc.). Nos deparamos com a mesma problemática apontada por Mallart (2014). Segundo ele, "a tentativa de proibir o acesso dos internos a determinados assuntos, sobretudo às notícias que têm como foco o tema da violência, constitui uma meta a ser alcançada pelos funcionários" (Mallart, 2014, p.107). Como estimular o pensamento crítico tendo a necessidade de negar os temas que lhes atravessam, como se esses não fossem de nosso interesse?

Ademais, a administração nos impôs a necessidade de certo distanciamento, o que, ao nosso ver, acabaria por estabelecer certa relação de classificação entre estudantes e educadores. Para sair da possível hierarquização nas relações, fizemos questão de participar das aulas também como atuantes do grupo, realizando os exercícios e jogos teatrais juntamente aos jovens, como integrantes ativas da pesquisa em processo.

\section{Das aulas no CASE (masculino)}

O tempo passado na prisão deve ser tempo de aprendizado, amadurecimento. A privação da liberdade, no espaço, deve intensificar o aproveitamento da liberdade no tempo. Temos que recusar o conceito de presídio-depósito, presídio-lixão. (Boal, 2003, p. 147).

Como coloca o teatrólogo brasileiro Augusto Boal20 (1931-2009), acreditamos que o período de privação de liberdade (já que existe) deve servir para oportunizar,

20 Augusto Boal (1931 - 2009) foi diretor, dramaturgo e teatrólogo brasileiro. Seu maior legado e marco de reconhecimento mundial foi a criação do Teatro do Oprimido (1987), fonte de pesquisa teórica e prática, tanto na elaboração dos planos de aula quanto na articulação do relato aqui exposto. 
às pessoas em conflito com a lei, alternativas outras de sobrevivência. O Teatro, nesse contexto, pressupõe possibilitar aos jovens o reconhecimento de que a privação de liberdade é reflexo da desigualdade social enfrentada por muitos.

A responsabilidade por tornar o Teatro interessante, atraente, bem quisto, nos era imensa, visto a ausência de familiaridade dos jovens com o Teatro que nos foi apresentado no contexto acadêmico ${ }^{21}$. Para tanto, escolhemos utilizar os jogos de iniciação teatral propostos por Boal, no intuito de desenvolver um trabalho de consciência corporal com os jovens, pois como colocou o autor (1977): "Podemos mesmo afirmar que a primeira palavra do vocabulário teatral é o corpo humano, principalmente fonte de som e movimento. Por isso, para que se possa dominar os meios de produção teatral, deve-se primeiramente conhecer o próprio corpo, para poder depois torná-lo mais expressivo" (Boal, 1977, p.131). Propomos aquecimentos corporais para posteriormente chegarmos aos jogos teatrais de (des)alienação corporal ${ }^{22}$ que envolviam exercícios de coordenação motora os quais utilizam posições corporais não convencionais.

O fazer teatral pareceu abstrato para a maioria das(os) jovens, por isso, vimos a necessidade de criar um caderno de registros pessoais para elas(es). Levamos os materiais (lápis e folhas sem grampos, de acordo com o permitido pela instituição) para que ilustrassem as capas com suas referências. Nas capas lê-se músicas de rap, máscaras de teatro, menções religiosas, além de desenhos de tatuagens, entre outros signos de linguagens que representam o universo que os permeiam.

Já na primeira aula surgiram assuntos importantes a serem considerados por quem trabalha com Teatro em espaços de vigilância, relacionados à sexualidade. Em determinado jogo, um dos rapazes interagiu mais de uma vez com um dos

${ }^{21}$ Acreditamos que exista teatralidade em manifestações pelas quais as(os) jovens nos demonstraram interesse como em novelas, filmes, linguagens corporais de batalhas de rap, etc. Não negamos a teatralidade nessas modalidades, mas nos referenciamos aqui, aos elementos que compõem a cena teatral - como iluminação, figurino, sonoplastia, etc. - e principalmente, a relação processual de contato com a linguagem cênica.

22 Pelo termo, compreende-se a alienação corporal como as restrições físicas ocasionadas por esforços repetitivos durante jornadas de trabalho. Boal nos sugere que, como primeiro passo para o fazer teatral, tornemos o corpo expressivo e livre do que nos caracteriza profissionalmente, (des)alienando, assim, nosso principal meio de produção: o corpo (Boal, 1997). 
condutores da oficina. A interação foi motivo para que o colega em questão fosse hostilizado pelos demais participantes. Presumimos que o motivo da piada era a interação do rapaz com o condutor da oficina, pois o condutor naturalmente performa certa liberdade com sua orientação sexual.

Ao encerrarmos a aula, como forma de compartilhamento da experiência vivenciada coletivamente, sugerimos que contassem para um determinado objeto, que circularia entre os participantes, suas percepções sobre nosso primeiro encontro. Cogitamos utilizar um caderno para o exercício (basicamente um diálogo), mas pressupomos que objeto era "feminino demais" 23 na ótica da autoafirmação masculina, pois sua capa possuía flores estampadas. Usamos então uma caneta. Optamos por ela ao caderno, pois a "feminilidade" do objeto poderia gerar certa repulsa nos jovens. Ao perceber que estes pequenos conflitos poderiam reafirmar algo que não acreditamos, recorremos aos estudos da psicanalista brasileira Susana Muszkat²4. A autora nos diz que:

O padrão de masculinidade denominada hegemônica baseia-se fundamentalmente no modelo patriarcal. [...] Associa virilidade e masculinidade à força física, prontidão sexual, coragem. Este homem é ainda provedor e emocionalmente forte, uma vez que fragilidade é algo associado ao universo feminino. Sendo assim, é necessário afastar-se de qualquer atributo vinculado ao mundo das mulheres, o que os leva a um comportamento homofóbico. O risco de uma aproximação de cunho afetivo com um outro homem pode levá-lo a ser mal-interpretado como alguém com pendores homossexuais. (Muszkat, 2006, p.19).

O Teatro neste contexto de autoafirmação masculina - tanto pela idade dos jovens, quanto pelo ambiente de vigilância ao qual estão sujeitos - parece ser propulsor de fragilidades aos olhos deles, portanto associado ao universo feminino.

${ }^{23}$ A utilização da aspas se deu pela ironia presente na afirmação. Não acreditamos que objetos possuem gênero. No entanto, no ambiente socioeducativo, percebemos que se mantém certos padrões embasados em caracterizações estereotipadas de: o que é masculino e o que é feminino. O último, sendo inferior e frágil em comparação ao primeiro, de acordo com a ótica patriarcal - reforçada em locais de vigilância.

${ }^{24}$ Muszkat é psicóloga pelo Instituto de Psicologia da Universidade de São Paulo (IP-USP) e psicanalista pela Sociedade Brasileira de Psicanálise de São Paulo (ABPSP), onde é membro efetiva e docente. É também formada em mediação de conflitos, tendo atendido famílias em situação de violência e coordenado grupos de reflexão de pessoas em situação de violência de gênero na ONG Pró-Mulher Família e Cidadania. É mestre em Psicologia Social pelo IP-USP e autora do livro Violência e masculinidade (2011). 
Sendo assim, o que é feminino é frágil, impreterivelmente. A abertura dos sentidos que o Teatro proporciona passou a ser encarada com a mesma ótica com as quais visualizam questões do universo feminino. Uma das maiores características dos jogos teatrais é proporcionar aos participantes experimentações e contatos. É colocá-los no lugar de observadores de ações e de fazedores delas. A prática teatral, ao nosso ver, facilita a escuta e difunde afetividade na relação com o próprio corpo e com o corpo do outro. Abordar determinadas questões, expressar nossas angústias e desejos ou simplesmente gerir o próprio corpo - neste caso, em liberdade cerceada - pode ser lido também como sinal de fragilidade.

Quando, num primeiro encontro, percebemos nos corpos dos jovens a resistência para somente olhar o colega, notamos a necessidade da prática teatral. A proposta de trocas de olhares (dentro do jogo) com alguém de fora de seu ciclo e do mesmo gênero (na ocasião, o condutor) desagradou suficientemente o coletivo para que nos perguntássemos o que eles entendem por homofobia. Essa opressão, já naturalizada e estruturada em nossa sociedade, que causa a morte diária de indivíduos LGBTQIA $+{ }^{25}$, tem sido abordada de alguma forma? Não existem outras orientações sexuais além das heteronormativas em ambientes de privação de liberdade? E seria o Teatro um aliado para discutir tais urgências? Questões essas que não tivemos respostas, tampouco nos contemplam o seu silenciamento.

Ao reconhecermos certo desinteresse dos jovens para com as atividades que propusemos na aula inaugural, e na tentativa de conquistar a atenção para o nosso trabalho, optamos por vincular o Teatro às técnicas de percussão corporal. A busca por uma nova metodologia visou aproximar o fazer artístico de seus cotidianos.

Em nosso terceiro encontro, o local estava mais movimentado do que o habitual e ao final desse, fomos informadas de que seria o último. O motivo: inspeção da juíza. Ao entrarmos para a aula de teatro, o chefe de segurança nos abordou dizendo que os jovens não queriam mais realizar as oficinas. Para

${ }^{25}$ A sigla LGBTQIA+ é utilizada para representar, respectivamente, pessoas que se identificam como Lésbicas, Gays, Bissexuais, Transexuais e Travestis, Queers, Intersexuais, Assexuadas e Aliadas, e o “+” representa todas as demais possibilidades de orientações sexuais e/ou identidades de gênero. 
compreendermos os motivos, propomos uma reunião no pátio com os jovens. Em roda, ouvimos suas opiniões: alguns desejavam continuar com as aulas, outros não queriam fazer nada no turno da prática (diziam já ter muitas demandas para cumprir).

Notamos que a vergonha de muitos era um dos empecilhos com relação às aulas de teatro, mas o motivo evidente das inquietações demonstrou-se, principalmente, através da postura dos agentes de segurança. A imposição por parte da equipe de segurança frente às aulas de Teatro diminuía nosso fazer artístico e pedagógico semanalmente. Tínhamos a sensação de que precisávamos provar, não só para os jovens, mas aos agentes que nosso trabalho era relevante.

Nossa relação com a equipe de agentes de segurança se resumia às corriqueiras saudações em entradas e saídas de aulas, entretanto, percebíamos que nossa presença na unidade masculina lhes causava certo estranhamento. Augusto Boal aborda aspectos dessa relação na passagem a seguir:

Temos que mostrar, em linguagem teatral, que os direitos humanos são humanos e se referem a todos os humanos, não apenas aos presos e suas famílias, mas também a eles, agentes: que um dos objetivos mais importantes dos direitos humanos é compreender o ser humano - direito e dever. Isto faz parte da função agente, que não se pode resumir apenas a guardador de chaves e usuário de cassetetes - ser agente deve ser uma função nobre, como a do médico e a do professor: ensina e ajuda a curar (Boal, 2003, p. 146).

Ao considerar Boal (2003) e de acordo com as atitudes dos agentes de segurança que nos acompanharam, percebemos que uma das dificuldades do trabalho foi a postura adotada por eles (oposta a postura sugerida por Boal) que no caso específico da nossa oficina, se resumiu em reprimir experiências que poderiam possibilitar o questionamento dos padrões vigentes. Ao nosso ver, as aulas de Teatro na ala masculina do regime socioeducativo passaram a enfrentar o que há de latente na sociedade: preconceitos gerados por uma estrutura social construída com base no patriarcado. 
[...] as mãos ficam sobre a mesa, imóveis, a postura ereta, as palavras escolhidas cuidadosamente - tudo transmite uma mensagem de absoluto respeito, como se eu fosse mais uma das guardas a quem ela deve se sujeitar todos os dias. A voz baixa vai ficando mais empolgada conforme o relato segue, mas continua se referindo a mim sempre como "senhora". Seu corpo internalizou a obediência, os olhos não (Queiroz, 2015, p.22).

A jornalista brasileira Nana Queiróz, em Presos que menstruam, a brutal vida das mulheres - tratadas como homens - nas prisões brasileiras ${ }^{26}$ (2015) nos relata histórias vividas por mulheres que enfrentam o cárcere pelos mais diversos motivos. Na obra, Queiróz salienta o fato de que as prisões masculinas foram, ao longo do tempo, "adaptadas" ao contexto feminino, pois a população carcerária de mulheres cresce exponencialmente no Brasil.

Ao equiparar, mais uma vez, o regime socioeducativo com prisões, em nossa primeira reunião, soubemos que as jovens na unidade feminina eram separadas fisicamente em duas alas, o que fez com que atuássemos dividindo a prática em dois momentos num mesmo turno. Em nosso encontro inaugural conseguimos identificar em cada uma delas grande disponibilidade e interesse para práticas artísticas. Mediante a criação de um contrato de respeito entre nós, a prática teatral possibilitou o entrosamento entre elas (internas) e nós (professoras em formação), o que facilitou o desenvolvimento de cada uma e do grupo, como um todo.

A prática teatral no setor feminino aconteceu pelo período de um semestre, e alcançamos resultados positivos no que tange fazeres pedagógicos e artísticos. Entretanto, o que nos interessa aqui é ressaltar acontecimentos circundados à prática: o que, com o Teatro, nos permitiu refletir sobre certas regras, já tão bem consolidadas, prevendo fissuras em sistemas coercitivos.

26 Ressaltamos estarmos atentas ao fato de que hoje, com as discussões latentes sobre LGBTfobia, entendemos que mulheres não necessariamente menstruam, bem como homens também podem menstruar. Isto por não terem nascido de acordo com suas atuais identidades de gênero. Neste caso, acreditamos que o título da obra esteja desatualizado. 
Raramente, encontrávamos espaço na ala feminina para travar diálogos sinceros com as agentes de segurança. Quando, em determinado momento, tivemos nosso trabalho prejudicado pela postura informal das agentes para com as atividades artísticas, respondemos com Teatro: em um de nossos encontros, as agentes de segurança estavam todas reunidas entre as duas alas conversando alto o suficiente para que tivéssemos dificuldade de sermos ouvidas pelas internas. Pedimos que falassem mais baixo, porém não fomos atendidas. Para aquela aula em específico, buscávamos retomar com as jovens aspectos do trabalho de atuação, desenvolvidos até então. Elas nos diziam o que julgavam ser crucial para entrar em cena, mas o barulho e as gargalhadas das agentes atrapalhavam nosso raciocínio. Então, decidimos jogar teatralmente. Solicitamos às alunas que se aproximassem da grade que as separava das agentes, e que anotassem em seus cadernos o que viam nos corpos e ações das agentes de segurança enquanto as observavam.

As jovens, inicialmente, temerosas com a possibilidade de serem repreendidas, passaram a se divertir vendo o desconforto das agentes de segurança ao serem observadas com afinco. Após dez minutos de silêncio e observação, retomamos o exercício a partir das percepções das internas. As jovens perceberam que, quando somos observadas, mudamos de postura. Através do Teatro, pudemos inverter a lógica de vigilância a que estão submetidas as jovens e em micro escala, mostramos às agentes o que é ter como realidade a sensação de constante observação, assim como vivem as jovens. A ação nos remeteu ao seguinte trecho da obra Teatro e Prisão:

Sim, o trabalho teatral provoca inúmeros questionamentos à estrutura da instituição prisional. Não é sem razão que o teatro luta para sobreviver em um contexto dominado pela ausência de interesse por aquele que deveria ser seu único objetivo de atenção, o processo de ressocialização dos apenados, e é encarado como opositor aos princípios de disciplina e segurança da unidade penal. (Concilio, 2008, p.150).

Considerando que o Teatro, como o visualizamos, tem em seu cerne a função de questionar a ordem vigente, passamos, em nossa prática, a identificar 
momentos em que com a arte seríamos capazes de tensionar os lugares de autoridade e, a partir da identificação desses momentos, suscitar o debate, mesmo que em micro escala sobre as estruturas opressivas já tão bem solidificadas no regime socioeducativo.

Outra informação relevante é a de que, no final do ano de 2019, a juíza responsável pelo DEASE autorizou a saída de cinco jovens da instituição para que pudessem assistir à apresentação da montagem da peça $A$ Cantora Careca ${ }^{27}$, do dramaturgo romeno Eugène Ionesco, encenada no CEART, no Campus I da Udesc. A ocasião permitiu que as jovens entrassem em ambiente universitário pela primeira vez e, no caminho de volta para a unidade, relataram interesse em fazer parte daquele universo - distante, na percepção delas, até então.

\section{Sair de cena estrategicamente: das finalizações no CASE e no CIF}

As perguntas que devemos nos fazer são: as prisões estão sendo espaços de real ressocialização como se propõe? Como surge essa ideia da privação de liberdade como uma pena para a quebra de convenções e contratos sociais? São as prisões as únicas formas de tratar certas quebras de acordos sociais? (Borges, 2019, p. 35).

Ao deslocar o pensamento de Borges (2019) para o contexto socioeducativo (que como vimos possui as mesmas características que as prisões convencionais, porém com medidas de penalidade abrandadas) observamos, desde a primeira aula na ala masculina, que os agentes insistiam em desmerecer os alunos enquanto eles faziam os exercícios. Quando nos predispomos a questionar tal postura, disseram-nos, através do setor pedagógico da unidade, que seria impossível respeitar professores que não correspondem aos padrões vigentes da heteronormatividade..$^{28}$

${ }^{27}$ Espetáculo produzido em 2019 por estudantes da $7^{\circ}$ fase das disciplinas de Montagem Teatral do curso de Licenciatura em Teatro da UDESC, com direção de Paulo Balardim e Fabiana Lazzari.

${ }^{28}$ A informação foi dada à pedagoga, que nos repassou constrangida os resultados de sua conversa com os agentes responsáveis pela ala masculina do socioeducativo. Segundo ela, o chefe de segurança a procurou findada nossa oficina para the dizer que "seria impossivel os agentes dele respeitarem um professor viado e uma professora que não depila os pelos do braço”. Este relato nos fez repensar nossas ações na ala 
A par da situação, nos perguntamos como fazer Teatro - prática que exige exposição sem amarras, liberdade de jogar e de se colocar no lugar de outrem em espaços em que o controle é a regra? Como convocar o outro ao jogo teatral em um local tão árido e repressor, que não consegue respeitar nossa existência? Enquanto promotores das práticas, aqueles que buscam preparar a aula de teatro como uma ação transformadora, nos perguntávamos como articular propostas que respeitassem as individualidades, interesses e identidades de pessoas que convivem diariamente com o comando repressor da vigilância. Em consonância ao que coloca Concilio (2008), concordamos que

Hoje, o teatro não é impedido de entrar na prisão; ele é impedido de permanecer, de se consolidar. O espetáculo pode até estrear, mas se ele vai conseguir atingir um número razoável de apresentações é uma outra questão. E assim o esforço redunda em uma certa sensação de desperdício, de impotência, de incapacidade de enfrentar o inimigo fatal que é a instituição. (Concilio, 2008, p.152).

Nessa perspectiva, mesmo que, ao abordar o Teatro em sistema prisional, e de fazê-lo a mais de uma década atrás, nos contempla em larga medida. Nossa prática foi impedida de permanecer no centro masculino de internação, sem que pudéssemos ao menos esboçar o potencial da arte teatral.

Após percebermos que não seria possível realizar práticas teatrais com os jovens no setor masculino, tentamos levar a eles a montagem do espetáculo solo Poeira $^{29}$, que fora apresentado na ala feminina da unidade. Ao solicitarmos a autorização do chefe de segurança - aquele mesmo que disse ser impossível conquistarmos o respeito dos agentes de segurança, tão somente por sermos quem somos - para entrar com a equipe do espetáculo na ala masculina, novamente fomos impedidos. A equipe de segurança argumentou que os jovens assistiriam a uma partida de futebol e que não thes interessaria o Teatro em comparação ao jogo. Ou seja, os jovens não são incentivados nem mesmo a assistir Teatro, a serem espectadores teatrais. A postura de negação frente às ações

masculina do socioeducativo, e interrompeu nosso trabalho.

${ }^{29}$ Atuação, dramaturgia e direção de Luan Renato Telles, graduando do curso de Licenciatura em Teatro da Universidade do Estado de Santa Catarina (UDESC). 
artísticas por parte do setor de segurança do regime socioeducativo nos distanciou do que almejávamos enquanto professoras em formação. Entretanto como colocou Concilio (2008), a experiência não nos limita, apenas ressalta a impressão que tínhamos desde nossa primeira reunião:

O desconforto da instituição perante o trabalho teatral, e vice-versa, é um princípio de trabalho, é parte integrante do contexto, e deve ser assumido como uma realidade a ser enfrentada diariamente por quem decide produzir arte atrás das grades. Não adianta reclamar da falta de apoio do presídio, não adianta perder tempo se insurgindo contra o tratamento pouco amigável dispensado pelos funcionários. Na maioria das vezes, o trabalho está apoiado no interesse pessoal dos artistas envolvidos e na crença de que aquele processo vai fazer sentido para os que dele participam. (Concilio, 2008, p.150).

Para além de contemplar pessoas que participam do processo, como coloca Concilio, intuímos efetuar - agora sobre o escrito - um compartilhamento que contemple também artistas e pesquisadoras que visam trabalhar nesses contextos. Acreditamos que o artigo cumprirá o papel de registrar aquilo que não é dito à quem inicia ações teatrais em privação de liberdade, justamente por serem assuntos transversais à prática. Entretanto, são fatores cruciais para a permanência da arte nestes locais.

Ao renunciarmos ao processo teatral na unidade masculina naquele momento - como sugestão do próprio setor pedagógico da unidade - percebemos que o faríamos muito em detrimento da permanência do trabalho na ala feminina do centro. Na posição em que estávamos, permanecer com as práticas na unidade masculina poderia interferir negativamente em nossa relação com as agentes e internas da unidade feminina. Como apontam as pesquisadoras brasileiras da área da psicologia, Luisa Bertrami D'Angelo e Jimena de Garay Hernandes (2017) em Sexualidade, um direito (secundário)? Atravessamentos entre sexualidade, socioeducação e punição,

Nas instituições de socioeducação, as violências de gênero e as relações desiguais de poder se atualizam através de práticas e discursos que cristalizam modelos hegemônicos de masculinidade e feminilidade, atrelados à heteronormatividade - entendida aqui como o 
estabelecimento e incessante manutenção de um modelo de ser, se relacionar e se projetar no mundo baseado na heterossexualidade e na complementaridade dos gêneros. (Junqueira, 2007, p.10 apud D’Angelo; Hernandez, 2017, p.94).

Essas experiências permanecem vivas em nós mesmo com as interrupções do projeto vinculado ao CASE e ao $\mathrm{CIF}^{30}$, e seguirão latentes, impulsionando nossas práticas e pesquisas, até que em algum momento nos surpreendamos com a possibilidade de articulação e mobilização do contexto repressor para um contexto emancipador. Descobrir fissuras dentro desse sistema rígido e coercitivo é encontrar a beleza e o potencial que, a nosso ver, a arte da cena transborda.

\section{Referências}

BOAL, Augusto. Teatro do oprimido e outras poéticas políticas. 2a Ed. Rio de Janeiro: Civilização Brasileira, 1977.

BOAL, Augusto. O Teatro como arte marcial. Rio de Janeiro: Garamond, 2003.

BORGES, Juliana. Encarceramento em massa. São Paulo: Sueli Carneiro, Pólen. 2019.

BRASIL, Lei № 8.069. Vide Lei no 13.869, de 2019 (Vigência). Dispõe sobre o Estatuto da Criança e do Adolescente e dá outras providências. De 13 de julho de 1990.

CONCILIO, Vicente. Teatro e Prisão: Dilemas da Liberdade Artística. São Paulo: Hucitec, 2008.

DAVIS, Angela. Estarão as prisões obsoletas?. 3a ed. Rio de Janeiro: Difel, 2019.

DAVIS, Angela. A liberdade é uma luta constante. 1a ed. São Paulo: Boitempo, 2018.

D’ANGELO, Luisa B.; HERNANDEZ, Jimena de G. Sexualidade, um direito (secundário)? Atravessamentos entre sexualidade, socioeducação e punição. In: PLURAL, Revista do Programa de Pós-Graduação em Sociologia da USP, São Paulo, v.24.1, 2017, p.78-104. Disponível em: <https://www.revistas.usp.br/plural/article/download/125958/133153/>. Acesso em: 23 set. 2020.

30 No ClF nossas ações foram interrompidas por conta da ameaça concreta de contágio pelo Covid-19. Tão logo sejam produzidas e disponibilizadas as desejadas vacinas, retornaremos a instituição. 
MALLART, Fábio. Cadeias Dominadas: a Fundação CASA, suas dinâmicas e as trajetórias de jovens internos. São Paulo: Terceiro Nome. 2014.

MUSZKAT, Susana. Violência e masculinidade: uma contribuição psicanalítica aos estudos das relações de gênero. 2006. 208 f. Dissertação (Mestrado em Psicologia) - Instituto de Psicologia - Universidade de São Paulo, São Paulo, 2006.

QUEIROZ, Nana. Presos que menstruam. Rio de Janeiro: Record, 2015.

ROCHA, Luiz Carlos da. A prisão dos pobres. 1994. Tese (Doutorado em Psicologia) - Instituto de Psicologia - Universidade de São Paulo, São Paulo, 1994.

SAFFIOTI, Heleieth I. B. Gênero, patriarcado, violência. São Paulo: Fundação Perseu Abramo, 2004.

VASSEN, Florian; KOUDELA, Ingrid Dormien. Teatro + - pedagogia do teatro: correspondências entre o teatro e a pedagogia do teatro. Revista A[L]Berto, v. 7, p. 11-20, 2014. Disponível em: <https://repositorio.usp.br/item/002760288>. Acesso em: 16 ago. 2020.

Recebido em: 08/10/2020

Aprovado em: 11/11/2020 